\title{
Relationship Between Erectile Dysfunction, the Neutrophil-to-Lymphocyte Ratio, and the Platelet-to-Lymphocyte Ratio
}

\author{
Mehmet Karabakan' (1), Aliseydi Bozkurt² (1) \\ ${ }^{1}$ Clinic of Urology, Mersin Toros State Hospital, Mersin, Turkey \\ 2Department of Urology, Erzincan University Mengücek Gazi Training and Research Hospital, Erzincan, Turkey
}

Cite this article as: Karabakan M, Bozkurt A. Relationship Between Erectile Dysfunction, the Neutrophil-to-Lymphocyte Ratio, and the Plateletto-Lymphocyte Ratio. JAREM 2019; 9(1): 27-31.

\begin{abstract}
Objective: Various chronic diseases, including hypertension (HT), diabetes mellitus (DM), and coronary artery disease (CAD), together with the medications used in the treatment of these conditions, are considered a part of the erectile dysfunction (ED) etiology. The neutrophilto-lymphocyte ratio (NLR) and the platelet-to-lymphocyte ratio (PLR) provide information about many diseases. The NLR and PLR increase in systemic inflammation, certain gynecological and gastrointestinal cancers, CAD, various oncological diseases, and especially in acute coronary syndromes. In this study, the relationship between PLR, NLR, and ED severity were examined in patients with ED.

Methods: All data from patients were screened retrospectively. Body mass index, the International Index of Erectile Function-5 (IIEF-5) scores, age, fasting blood glucose, whole blood count, lipid, and hormone profile values were measured. The PLR and NLR values from both the patient and control groups were evaluated. The IIEF-5 questionnaire was used to measure the quality of erection in all the groups. A total of 131 patients with ED were divided into four groups: severe (34 patients), moderate (32 patients), mild-to-moderate (36 patients), and mild ED (29 patients). In addition, a control group was formed with 26 healthy men.

Results: No statistically significant difference was observed between the groups in terms of the mean age, hypertension, smoking status, alcohol use, DM, CAD, and cholesterol and triglycerides levels. The mean PLR values were 125.3 $\pm 41.4,120.6 \pm 36.1,118.2 \pm 50.4,104.9 \pm 3.2$, and $107.5 \pm 37.4$ in the severe, moderate, mild-to-moderate, mild ED, and control groups, respectively. There was no significant difference in the PLR ratio among the ED groups and controls ( $p>0.05$ ). The mean NLR values were $2.40 \pm 1.22,2.34 \pm 0.88,2.26 \pm 1.22,2.1 \pm 0.87$, and $1.76 \pm 0.7$ in the severe, moderate, mild-to-moderate, mild ED, and control groups, respectively. Compared with the control group, this value was statistically significant for patients with all ED groups $(p<0.05)$.

Conclusion: The NLR value was found to be higher in patients with ED. The NLR value may be related to ED, and it can give valuable information in patients with ED.
\end{abstract}

Keywords: Erectile dysfunction, neutrophil-to-lymphocyte ratio, platelet-to-lymphocyte ratio

\section{INTRODUCTION}

Erectile dysfunction (ED) is the most frequently treated sexual malfunction. It is described as not being able to establish necessary erection for a satisfying sexual intercourse or to sustain it (1). The most frequent reasons underlying ED etiology are hypertension $(H T)$, diabetes mellitus (DM), and coronary artery disease (CAD); and drugs used for these diseases have negative effects (2). The common mechanism underlying these diseases can be the endothelial dysfunction resulting in degenerative changes (3). ED in males having endothelial dysfunction but lacking atherosclerosis evidence is considered as an early indicator for CAD

(4). The relationship between ED and increased risk of cardiovas- cular events can be explained by underlying endothelial dysfunction. Endothelial dysfunction is usually defined as impaired nitric oxide bioavailability, decreased vasodilatation, and worsened inflammation prior to atherosclerotic lesions (5). Recent studies have shown that atherosclerosis is an active inflammatory period rather than a passive vascular damage caused by lipid infiltration $(6,7)$.

Neutrophil/lymphocyte ratio (NLR), which is suggested as a biomarker for subclinical inflammation, has been shown to be in relation with prognosis both in CAD and cardiac failure $(8,9)$. Again, thrombocyte/lymphocyte ratio (TLR) has been detected as an important marker for inflammation. Recent studies have 
shown the strong relation of TLR with important cardiovascular unfavorable consequences and atherosclerosis $(10,11)$. NLR and TLR increase in systemic inflammation, specific gynecologic and gastrointestinal cancers and cardiovascular diseases $(12,13)$. Low-grade subclinical inflammation can affect endothelial function, and can induce prothrombotic events. In many studies, the start and strength of ED have been shown to be in close association with increased levels of inflammation biomarkers $(14,15)$. This study investigated the relation between ED and NLR and TLR levels.

\section{METHODS}

After obtaining approval from the local ethics committee, data of 131 patients who were referred with ED were screened; and the cases were grouped into four: strong ED (34 cases), moderate ED (32 cases), mild-moderate ED (36 cases), and mild ED (29 cases). Also, the control group was consisted of 26 healthy males.

All patients had ED complaints in their sexual intercourses within the last six days. The data of the ED cases were obtained from our urology clinic, while the control group was formed by the data of healthy individuals. All patients' erection functions were determined according to International Index of Erectile Function (IIEF-5) (16). The participants were grouped as 5-7, 8-11, 12-16, 17-21, and 22-25 for strong ED, moderate ED, mild-moderate, mild, and the control group, respectively. All participants were sexually active, and they had completed the IIEF-5 questions based on their sexual activity in the last six months.

The patients who had a neurological disease, psychogenic ED, urogenital, gynecological and gastrointestinal cancer history, pelvic trauma history, anemia, psychiatric disorder, thyroid disease, acute or chronic urinary system disease, or recent kidney disease as well as participants who used drugs within three months from the initiation of the project that may affect the sex hormone levels and the vitamin metabolism, or who are under treatment for ED were excluded from the study.

\section{Medical History and Physical Examination}

All participants' medical information, including past medical history, hypertension, smoking, alcohol consumption, sexual dysfunction duration, and age, was gathered. Physical examination included rectal touch, height-weight measurement, and body mass index (BMI). BMI was calculated by the division of weight (in $\mathrm{kg}$ ) to height (in $\mathrm{m}$ ) square $\left(\mathrm{kg} / \mathrm{m}^{2}\right)$. Cases suspected of prostate cancer or hypogonadism were excluded from the study.

\section{Laboratory Analysis}

Fasting blood sugar (FBS), total testosterone (TT), triglycerides (TG), low-density lipoprotein cholesterol (LDL), and high-density lipoprotein cholesterol (HDL) levels were measured. Serum testosterone level was measured by enzyme-linked immunosorbent assay method (Siemens Centaur XP Kit, Germany).
Neutrophil/lymphocyte ratio was calculated by dividing neutrophil number to lymphocyte number; and TLR was calculated by dividing thrombocyte number to lymphocyte number.

\section{Statistical Analysis}

The data were evaluated using the Statistical Package for Social Sciences version 20.0 (IBM Corp., Armonk, NY, USA) statistical package program. Variables mean \pm standard deviation and percentage and frequency values were used. In addition, the homogeneity of the variances, which is the prerequisite of the parametric tests, was checked by the "Levene's test." The assumption of normality was evaluated with the Shapiro-Wilk test. For the comparison of three and more groups, one-way analysis of variance test was used. When Tukey HSD test, multiple comparison test, could not be used, Kruskal-Wallis and Bonferroni-Dunn tests were applied.

The relationship between the two variables was evaluated by Pearson correlation coefficient; and when it did not meet the parametric test prerequisites, Spearman correlation coefficient was used. The relationships between categorical variables were analyzed by Fisher's exact test and chi-square test. In cases where the expected frequencies were less than 20\%, "Monte Carlo Simulation Method" was used for the inclusion of these frequencies in the analysis. $p<0.05$ was considered statistically significant.

\section{RESULTS}

The average age of the participants were $57.8 \pm 8.6$ years, $52.9 \pm 8.8$ years, $56.2 \pm 6.9$ years, $51.3 \pm 8.4$ years, and $53.3 \pm 8.3$ years in the strong $E D$, moderate $E D$, mild-moderate $E D$, mild ED, and the control group, respectively. Statistically significant difference was not detected between the groups in terms of the average age, hypertension, smoking, alcohol consumption, DM, CAD, LDL, HDL, total cholesterol, and TG levels. The data are shown in Table 1. Serum testosterone levels were detected as $438.3 \pm 148.1 \mathrm{ng} / \mathrm{dL}$, $458.5 \pm 155.4 \mathrm{ng} / \mathrm{dL}, 366.19 \pm 92.9 \mathrm{ng} / \mathrm{dL}, 422.8 \pm 128.1 \mathrm{ng} / \mathrm{dL}$, and $485.5 \pm 172.5 \mathrm{ng} / \mathrm{dL}$ in the strong ED, moderate ED, mild-moderate $E D$, mild ED, and the control group, respectively. Between the groups, statistically significant difference was detected $(p<0.05)$. The average TLRs were 125.3 $\pm 41.4,120.6 \pm 36.1,118.2 \pm 50.4$, $104.9 \pm 34.2$, and $107.5 \pm 37.4$ in the strong $E D$, moderate $E D$, mildmoderate ED, mild ED, and the control group, respectively. There was no significant difference between ED and the controls in terms of TLR ( $p>0.05)$. The average NLR values were $2.40 \pm 1.22$, $2.34 \pm 0.88,2.26 \pm 1.22,2.1 \pm 0.87$, and $1.76 \pm 0.7$ in the strong $E D$, moderate ED, mild-moderate ED, mild ED, and the control group, respectively. When compared to the control group, these levels were found significant in the strong ED, moderate ED, mildmoderate ED groups; but significant difference was not detected between the mild RD group and the controls ( $p>0.05$ ).

\section{DISCUSSION}

Erectile dysfunction is mostly a disease of vascular origin. It has many common risk factors with cardiovascular diseases, such as 
Table 1. Clinical data and fasting endocrine values of the participants

\begin{tabular}{|c|c|c|c|c|c|c|}
\hline Groups & $\begin{array}{c}\text { Severe ED } \\
n=34\end{array}$ & $\begin{array}{c}\text { Moderate ED } \\
\qquad n=32\end{array}$ & $\begin{array}{l}\text { Mild-moderate E[) } \\
\qquad n=36\end{array}$ & $\begin{array}{l}\text { Mild ED } \\
n=29\end{array}$ & $\begin{array}{l}\text { Control } \\
n=26\end{array}$ & $p$ \\
\hline \multicolumn{7}{|l|}{ Clinical data } \\
\hline Age (year) & $57.8 \pm 8.6$ & $52.9 \pm 8.8$ & $56.2 \pm 6.9$ & $51.3 \pm 8.4$ & $53.3 \pm 8.3$ & 0.329 \\
\hline BMI $\left(\mathrm{kg} / \mathrm{m}^{2}\right)$ & $26.0 \pm 3.1$ & $25.5 \pm 2.7$ & $26.3 \pm 2.3$ & $24.9 \pm 2.1$ & $27.3 \pm 2.2$ & 0.254 \\
\hline Alcohol consumption (\%) & 26 & 22 & 16.7 & 17 & 18.3 & 0.38 \\
\hline Smoking (\%) & 20.7 & 27.6 & 27.6 & 13.8 & 10.3 & 0.38 \\
\hline IIEF-5 & $6.17 \pm 0.6$ & $9.1 \pm 0.7$ & $12.7 \pm 1.4$ & $18.3 \pm 1.5$ & $24.2 \pm 1.12$ & 0.001 \\
\hline $\mathrm{TT}\left(\mathrm{ng} \mathrm{dL}^{-1}\right)$ & $438.3 \pm 148.1$ & $458.5 \pm 155.4$ & $366.2 \pm 92.9$ & $422.8 \pm 128.1$ & $485.5 \pm 172.5$ & 0.015 \\
\hline Total cholesterol (mg/dL) & $192.8 \pm 53.1$ & $190.1 \pm 32.9$ & $193.9 \pm 33.1$ & $205.7 \pm 28$ & $218.3 \pm 28.1$ & 0.415 \\
\hline TG & $184.24 \pm 63.72$ & $171.8 \pm 62.1$ & $181.1 \pm 68.5$ & $181.8 \pm 76.8$ & $155.9 \pm 58.6$ & 0.387 \\
\hline HDL & $40.9 \pm 6.7$ & $41.3 \pm 11.0$ & $41.6 \pm 7.9$ & $40.2 \pm 10.2$ & $41.8 \pm 8.2$ & 0.717 \\
\hline LDL & $115.6 \pm 35.1$ & $123.1 \pm 30.1$ & $117.3 \pm 27.2$ & $131.4 \pm 30.2$ & $126 \pm 35.5$ & 0.419 \\
\hline NLR & $2.4 \pm 1.22$ & $2.34 \pm 0.88$ & $2.26 \pm 1.22$ & $2.08 \pm 0.87$ & $1.76 \pm 0.7$ & 0.044 \\
\hline PLR & $125.3 \pm 41.4$ & $120.6 \pm 36.1$ & $118.2 \pm 50.4$ & $104.9 \pm 34.2$ & $107.5 \pm 37.4$ & 0.130 \\
\hline
\end{tabular}

CAD, age, HT, DM, obesity, smoking, and metabolic syndrome $(5,17)$. ED itself is not only a strong predictive value for CAD but also a predictor of deaths related to serious cardiovascular events in males with CVD in the future (18). Studies have shown that inflammation is important in the initiation and progression of atherosclerosis, and it plays a role in the transformation of a stable atherosclerotic lesion into an unstable plaque (19). Recent studies have shown that the onset and severity of ED are closely related to highly inflammatory markers, and that these markers (e.g., CRP, interleukin (IL) -6, IL-10, IL-1 $\beta$, and TNF-a) show increased production in patients $(14,15,20)$. It has been shown that NLR, which is found to be associated with subclinical inflammation, and TLR, which is an important indicator of inflammation, have strong relations with cardiovascular negative results and atherosclerosis (8-11). In addition, in the recent studies, both NLR and TLR were associated with ED (21).

Lately, the well-known relationship between atherosclerosis and ED as well as the significant association of cardiac diseases with TLR and NLR has led to the investigation of TLR and NLR in patients with ED. In a recent study by Sambel et al. (21), both NLR and TLR values were significantly higher in patients with
ED compared to those in the control group. In that study, however, NLR and TLR values were not correlated with ED severity. Again in a study by Akbaş et al. (22), TLR value was higher in patients with ED compared to that in the control group. Also, in that study, the correlation of TLR value with ED severity was determined. However, in our study, the NLR ratio was found to be higher in patients with ED compared to that in the control group, but there was no significant difference in the TLR values within the two groups. This significant difference in the NLR values can only be explained by its close association with atherosclerosis. Kalay et al. (23) reported that NLR was higher in patients with atherosclerosis, and Demirkol et al. (24) found that NLR was significantly higher in patients with cardiac syndrome $X$ and CAD. In many studies, TLR has been reported to be in close association with inflammation (25), and a tight association of TLR with major adverse cardiovascular outcomes and atherosclerosis have been shown $(11,26)$. Also, in cases of inflammation, increased platelet count can be seen in patients with active atherosclerosis, and it has been found to be correlated with the severity of atherosclerosis (25). Although there was no significant difference between the TLR values in 
our study, the mean TLR values were higher in the severe, moderate, and mild-moderate ED group compared to those in the control group.

Our findings suggest that NLR and TLR may support the diagnosis of atherosclerosis in ED etiology. We believe that in the evaluation of ED, NLR is more valuable than TLR. The limitation of our study was the absence of penile Doppler ultrasonography in the small participant groups and patients with ED.

\section{CONCLUSION}

There is a need for comprehensive and multicenter studies in the use of NLR and TLR for the evaluation of ED from vascular origin in patients with $\mathrm{ED}$.

Ethics Committee Approval: Ethics committee approval was received for this study from the Ethics Committee of Erzincan University School of Medicine (24.01.2018).

Informed Consent: Informed consent was not taken from patients due to the retrospective nature of the study.

Peer-review: Externally peer-reviewed.

Author Contributions: Concept - M.K., A.B.; Design - M.K., A.B.; Supervision - M.K.; Resources - A.B.; Data Collection and/or Processing - A.B.; Analysis and/or Interpretation - M.K.; Literature Search - M.K., A.B.; Writing Manuscript - M.K.; Critical Review - M.K., A.B.

Conflict of Interest: The authors have no conflict of interest to declare.

Financial Disclosure: The authors declared that this study has received no financial support.

\section{REFERENCES}

1. Porst H, Burnett A, Brock G, Ghanem H, Giuliano F, Glina S, et al. SOP conservative (medical and mechanical) treatment of erectile dysfunction. J Sex Med 2013; 10: 130-71. [CrossRef]

2. Shaeer O, Shaeer K. The Global Online Sexuality Survey (GOSS): erectile dysfunction among Arabic-speaking internet users in the Middle East. J Sex Med 2011; 8: 2152-60. [CrossRef]

3. Berrada S, Kadri N, Mechakra-Tahiri S, Nejjari C. Prevalence of erectile dysfunction and its correlates: a population-based study in Morocco. Int J Impot Res; 2003: 15: 3-7. [CrossRef]

4. Vlachopoulos C, Rokkas K, loakeimidis N, Stefanadis C. Inflammation, metabolic syndrome, erectile dysfunction, and coronary artery disease: common links. Eur Urol 2007; 52: 1590-600. [CrossRef]

5. Yao F, Huang Y, Zhang Y, Dong Y, Ma H, Deng C, et al. Subclinical endothelial dysfunction and low-grade inflammation play roles in the development of erectile dysfunction in young men with low risk of coronary heart disease. Int J Androl 2012; 35:653-9. [CrossRef]

6. Libby P. Molecular basis of the acute coronary syndromes. Circulation 1995; 91: 2844-52. [CrossRef]

7. Falk $E$, Shah $P$, Fuster V. Coronary plaque disruption. Circulation 1995; 92: 657-71. [CrossRef]

8. Tamhane UU, Aneja S, Montgomery D, Rogers EK, Eagle KA, Gurm HS. Association between admission neutrophil to lymphocyte ratio and outcomes in patients with acute coronary syndrome. Am J Cardiol 2008; 102: 653-7. [CrossRef]

9. Uthamalingam S, Patvardhan EA, Subramanian S, Ahmed W, Martin W, Daley $M$, et al. Utility of the neutrophil to lymphocyte ratio in predicting long-term outcomes in acute decompensated heart failure. Am J Cardiol 2011; 107: 433-8. [CrossRef]

10. Azab B, Shah N, Akerman M, McGinn JT Jr. Value of platelet/ lymphocyte ratio as a predictor of all-cause mortality after non-ST elevation myocardial infarction. J Thromb Thrombolysis 2012; 34: 326-34. [CrossRef]

11. Yuksel M, Yildiz A, Oylumlu M, Akyuz A, Aydin M, Kaya H, et al. The association between platelet/lymphocyte ratio and coronary artery disease severity. Anatol J Cardiol 2015; 15: 640-7. [CrossRef]

12. Bhat T, Teli S, Rijal J, Bhat H, Raza M, Khoueiry G, et al. Neutrophil to lymphocyte ratio and cardiovascular diseases: a review. Expert Rev Cardiovasc Ther 2013; 11: 55-9. [CrossRef]

13. Proctor MJ, McMillan DC, Morrison DS, Fletcher CD, Horgan PG, Clarke SJ. A derived neutrophil to lymphocyte ratio predicts survival in patients with cancer. Br J Cancer 2012; 107: 695-9. [CrossRef]

14. Arana Rosainz Mde J, Ojeda MO, Acosta JR, Elías-Calles LC, González NO, Herrera OT, et al. Imbalanced low-grade inflammation and endothelial activation in patients with type 2 diabetes mellitus and erectile dysfunction. J Sex Med 2011; 8: 2017-30. [CrossRef]

15. Bocchio M, Desideri G, Scarpelli P, Necozione S, Properzi G, Spartera $\mathrm{C}$, et al. Endothelial cell activation in men with erectile dysfunction without cardiovascular risk factors and overt vascular damage. J Urol 2004; 171: 1601-4. [CrossRef]

16. Rosen RC1, Riley A, Wagner G. The international index of erectile function [IIEF]: a multidimensional scale for assessment of erectile dysfunction. Urology 1997; 49: 822-30. [CrossRef]

17. Raheem OA, Su JJ, Wilson JR, Hsieh TC. The Association of Erectile Dysfunction and Cardiovascular Disease: A Systematic Critical Review. Am J Mens Health 2017; 11: 552-63. [CrossRef]

18. Montorsi F, Briganti A, Salonia A, Rigatti P, Margonato A, Macchi A, et al. Erectile dysfunction prevalence, time of onset and association with risk factors in 300 consecutive patients with acute chest pain and angiographically documented coronary artery disease. Eur Urol 2003; 44: 360-4. [CrossRef]

19. Ross $R$, The pathogenesis of atherosclerosis: a perspective for the 1990s. Nature 1993; 362: 801-9. [CrossRef]

20. Vlachopoulos C, Aznaouridis K, loakeimidis N, Rokkas K, Vasiliadou C, Alexopoulos N, et al. Unfavourable endothelial and inflammatory state in erectile dysfunction patients with or without coronary artery disease. Eur Heart J 2006; 27: 2640-8. [CrossRef]

21. Sambel M, Kilic M, Demirbas M, Onen E, Oner S, Erdogan A, et al. Relationship between erectile dysfunction and the neutrophil to lymphocyte and platelet to lymphocyte ratios. Int J Impot Res 2018; 30: 27-35. [CrossRef]

22. Akbas A, Gulpınar MT, Sancak EB, Gunes M, Ucar M, Altok M, et al. The relationship between platelet-lymphocyte ratio and severity of erectile dysfunction. Kaohsiung J Med Sci 2016; 32: 91-5. [CrossRef]

23. Kalay N, Dogdu O, Koc F, Yarlioglues M, Ardic I, Akpek M, et al. Hematologic parameters and angiographic progression of coronary atherosclerosis. Angiology 2012; 63: 213-7. [CrossRef] 
24. Demirkol S, Balta S, Unlu M, Arslan Z, Cakar M, Kucuk U, et al. Neutrophils/lymphocytes ratio in patients with cardiac syndromeX and its association with carotid intima-media thickness. Clin Appl Thromb Hemost 2014; 20: 250-5. [CrossRef]

25. Gary T, Pichler M, Belaj K, Hafner F, Gerger A, Froehlich H, et al. Platelet-to-lymphocyte ratio: a novel marker for critical limb ische- mia in peripheral arterial occlusive disease patients. PLoS ONE 2013; 8: e67688. [CrossRef]

26. Sunbul M, Gerin F, Durmus E, Kivrak T, Sari I, Tigen K, et al. Neutrophil to lymphocyte and platelet to lymphocyte ratio in patients with dipper versus non-dipper hypertension. Clin Exp Hypertens 2014; 36: 217-21. [CrossRef] 